\title{
Using Case Histories to Teach Parasitology Labs
}

\section{Tamila L. McMullan ${ }^{1}$ and Heather Coatsworth ${ }^{2}$}

\author{
${ }^{1}$ Simon Fraser University, Department of Biological Sciences, 8888 University Dr, Burnaby BC \\ V5A 1S6 CAN \\ ${ }^{2}$ University of Florida, Department of Infectious Diseases and Immunology, 2055 Mowry Rd, \\ Suite 250, Gainesville FL 32610 USA \\ (tmcmulla@sfu.ca; h.coatsworth@ufl.edu)
}

\begin{abstract}
Case histories were added to the BISC318 Parasitology lab at Simon Fraser University (Burnaby British Columbia, Canada) and the lab exams were changed to match this new format. The case histories resembled parasitological whodunnits, consisting of a patient background, pictures, as well as knowledge testing questions. Each group of 3-4 students was given four randomly assigned case histories per lab. The groups worked through the histories one by one, discussing their results with an instructor. The lab exams were individual assessments and consisted of ten novel case histories. An anonymous student survey after the lab midterm in 2018 revealed that students preferred the case history exam format; that the difficulty was matched (or harder) to other types of lab exams; and demonstrated their knowledge better. The 2018/2019 case history classes did as well or better on all types of lab exam questions and earned higher overall grades for the course.
\end{abstract}

Keywords: parasitology, case history, active learning, laboratory teaching

Link to Original Poster File: https://doi.org/10.37590/able.v41.poster74

\section{Introduction}

In recent years, there has been a movement to include active learning activities in university courses, and studies have shown that students achieve higher grades and are more satisfied with a course when it has these activities (Freemann 2014). In 2017, we (Tamila (Tammy) McMullan, (Senior Lecturer), Heather Coatsworth (Teaching Assistant), Dr. Carl Lowenberger (Professor), and Tiia Haalapinien (Teaching Technician)) decided to change the lab component of BISC318 Parasitology, to include active learning activities. One of the challenges of teaching Parasitology at the undergraduate level is how to cover this vast subject in the allotted time - there are more parasites than non-parasitic organisms on Earth (Acholonu 2003). To start the process of revising the course, we looked at how other universities, both within Canada and internationally, had structured their undergraduate Parasitology courses. We found that the majority of undergraduate Parasitology courses are taught with a lecture and lab component $56 \%$ of the courses surveyed online). The remainder of the courses only had lectures $(39 \%)$ or were completely online $(5 \%)$. Jabbar et al (2016) discussed how digital technologies may be used to teach Parasitology, including gamification (the use of game design elements in non-game context) and they discussed the online use of case histories. After much discussion, we decided to add case histories to the lab component of the course in 2018. The case histories were also used in 2019 when Heather Coatsworth taught the entire course as a Sessional Instructor, with Nicolas Salcedo (NS) as a Teaching Assistant.

The case histories worked in conjunction with the lab specimens that we have in the Department's teaching collection. The only changes in the course were the addition of the case histories and the format of the lab exams. We used the same specimens, lab handouts, lab introductory talks and all the teaching staff were the same (2018). Although this paper addresses the lab component of the course, it is worth noting that the lecture material remained the same during this time. Each week of the lab dealt with a different taxonomic group of parasites. This Parasitology course is one semester in length (13 weeks) and has three hours of lecture and three hours of lab per week.

\section{The Case Histories}

The most frequent question we were asked in the lab was "Where do the case histories come from?". We did 
not provide the students with this information. For each week, 11-17 case histories were written (this number varied with the number of species we examined in the lab that week). The case histories were based upon articles published in the primary literature, parasite related websites (Creepy Dreadful Wonderful Parasites https://parasitewonders.blogspot.com; Center for Disease Control and Prevention https://www.cdc.gov/dpdx/ monthlycasestudies/2019/index. html) and a few were original compositions. Heather Coatsworth (HC) wrote three Case Histories for Lab 1. The remainder of the case histories were written by Tammy McMullan (TM). We each proofread the other's case histories before they were used in the lab. The case histories were written to read as parasitological whodunnits.

Each case history would start with a short introduction about the history of the patient (human or other animal), and any relevant information about where they traveled or lived, what they ate, activities they did and the symptoms they were experiencing. The case history then listed the tests and subsequent results from the doctor or veterinarian, if there was medication prescribed, and an update on the patient's condition. Following this, a number of questions were posed. Images included in the case histories were sourced online. The photographs which were selected were purposely not the best representation of the parasite (to push students to examine the entirety of the information presented), but were clear enough to be diagnostic to students who had a working knowledge of the course material (as these parasites were observed in the same lab session via microscopy prior to the case history discussion).

Two examples of the case histories that we developed are shown in Figure 1. Students were given color versions of the case histories.

In the lab, after the introductory talk, the students examined the available specimens. Once the students were familiar with all the specimens and had time to review their notes from lecture and the lab, they would form a group (3-4 students per group) and ask for their first case history. Each group would be given a total of four randomly assigned case histories each week; however, the groups were only given one case history at a time. The students worked together to answer the questions posed in the case history. The students were not allowed to use their notes, lab handouts or the internet when working on the case histories. When they thought they could correctly answer all the questions in the case history, the students would then ask one of the laboratory instructors (HC, TM or NS) to review the group's answers to the questions. If the group had incorrectly identified the parasite, the instructor would ask them to go back and look at the case history again and ask the instructor to come back when they were ready. If the group was correct on their identification of the parasite, then the instructor would go through all the questions with the students.
During these discussions, the instructor had the opportunity to pass on other tidbits of information which may not have been included in the handout or lectures (i.e. how socioeconomic factors have changed in certain countries over time, behaviours that increase the risk of acquiring a parasite, the importance of stating whether the parasite was Entamoeba coli or Escherichia coli and not just use $E$. coli). The instructor was also able to ask the group what information from the case history they used to inform their decision, and potentially point out other hints that the case history may have provided. The discussions about each case history served as an excellent re-iteration of the lecture and lab material and provided students with a chance to recollect knowledge in an approachable, nongraded atmosphere. Instructors did their best to monitor that all members of each group were participating.

\section{Evaluation}

Prior to 2018, the lab material was evaluated based upon typical station exams, where each station would have a specimen and the students were required to answer questions about the specimen and its biology. In 2018 and 2019, the lab exams consisted of ten novel case histories (species examined were randomly selected from the parasites that the students had worked with in the lab). The case history lab midterm and final exams were individual assessments of each student's knowledge. The students were given exams with color images and these images were the best images that were available. The maximum time allotted for the midterm lab exam was 120 minutes. Based upon student feedback, an additional 15 minutes was added to the final lab exam (total of 135 minutes) in 2018, but not in 2019 .

\section{Post-Midterm Lab Exam Survey}

In 2018, in the week after the lab midterm exam, and before the students were allowed to see their graded exams, the students were asked to complete a voluntary anonymous survey. The results of the post-midterm lab exam survey are located in Figure 2.

It is important to note that the majority of students thought the case history lab midterm exam level of difficulty was similar or harder than traditional station lab exams that they had written in other 300 level (third year) courses and better at demonstrating their overall knowledge of the lab material.

As you can see from the 'Actual' distribution of letter grades graph at the bottom right of Figure 2, the students did much better on the lab midterm than they thought they did. The Department of Biological Sciences has an internal document which is a guideline for faculty to use when assigning letter grades for a course, this guideline was used for the letter grade assignment in the 'Actual' graph.

The 2019 class was not asked to complete the postlab midterm survey so that data is not available. 


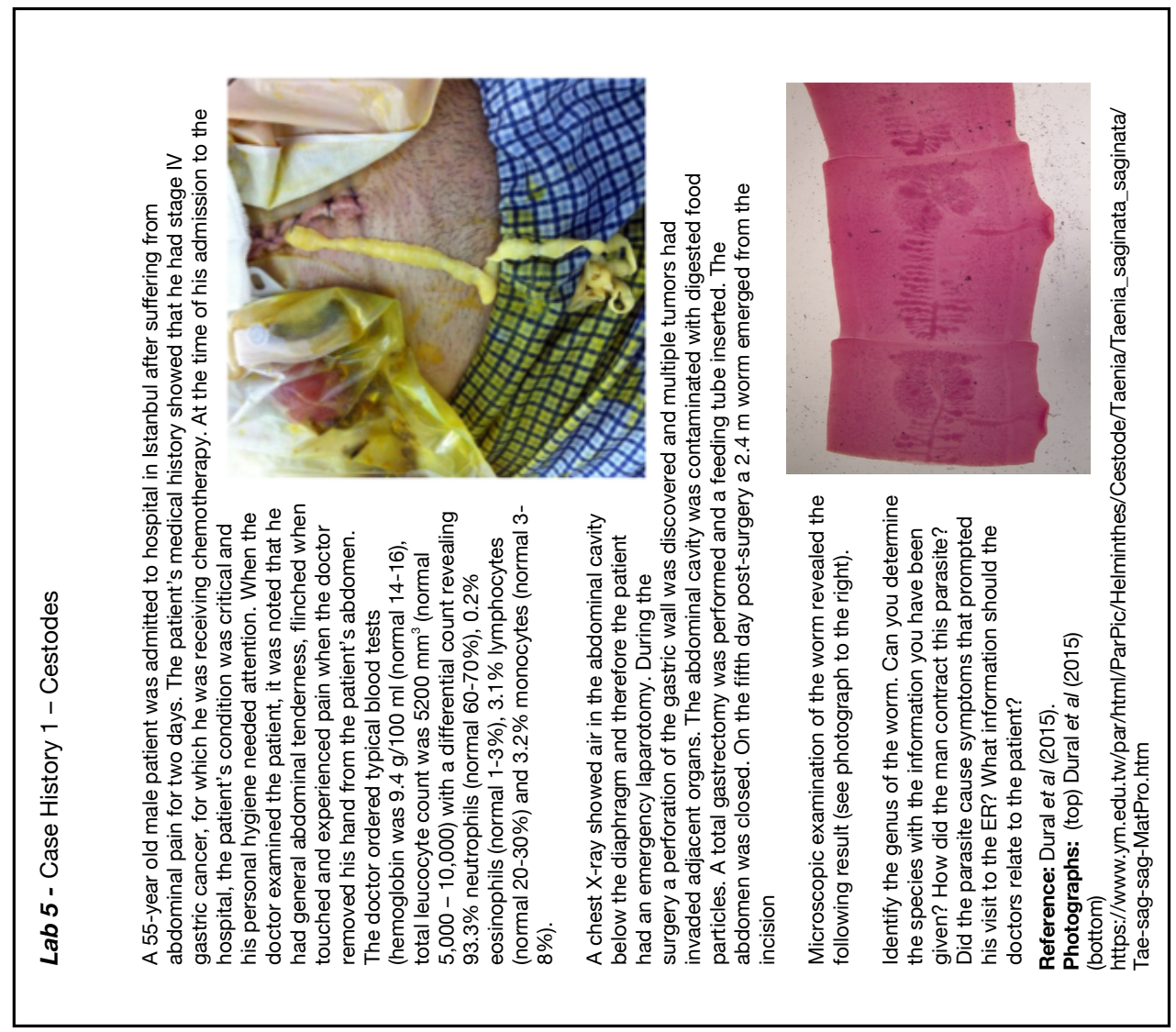

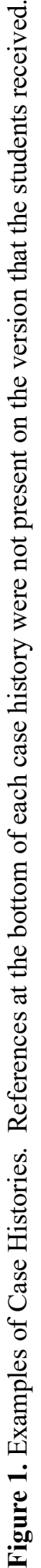


Question 1 Have you ever written a 300-level $\left(3^{\text {rd }}\right.$ year) station lab exam? $84.6 \%$ Yes

Question 2 On average how do you rate the 300 level station lab exams that you have written to this point in your academic career?

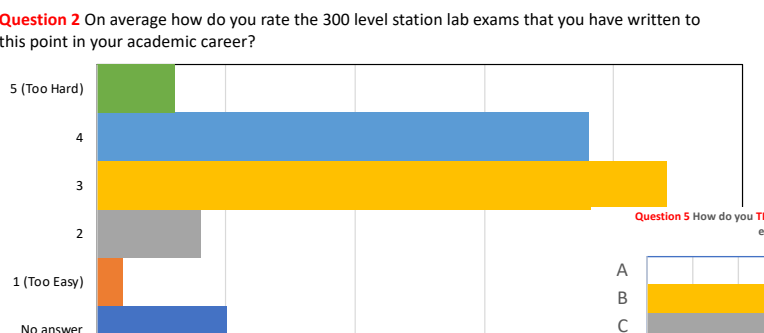

Question 3 When you compare the case history lab midterm exam for BISC318 to the 300 level station lab exams that you have written up to this point, rate the difficulty of the case history midterm exam.

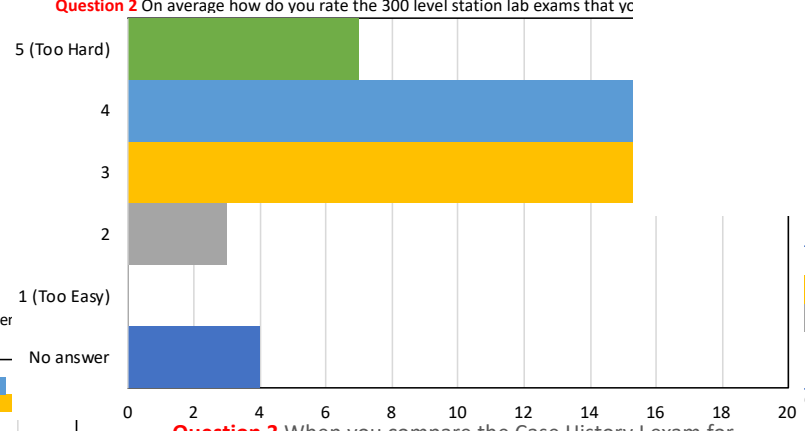

Question 4 Do you think that the case history lab midterm exam was better at demonstrating your overall knowledge of the lab material than a typical station lab exam?

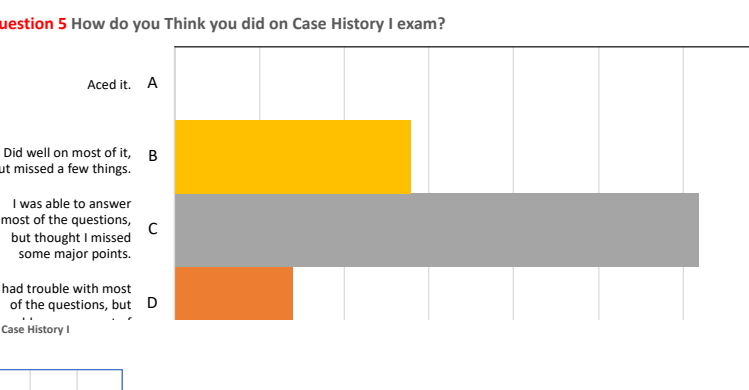

Question 5 How do you think you did on the case history lab midterm exam?

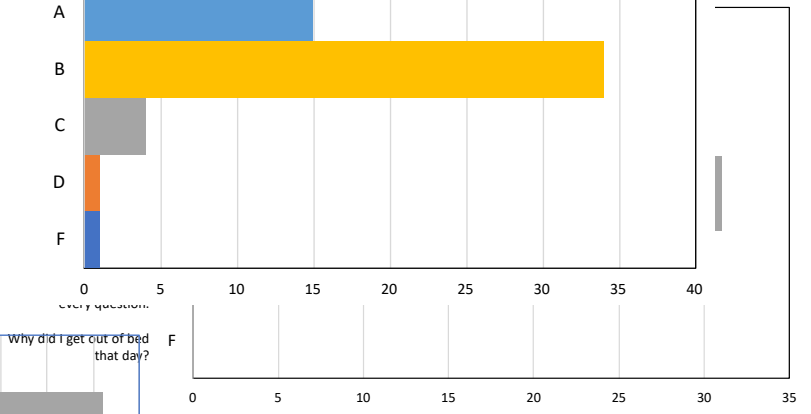

How the class actually did on case history lab midterm exam?

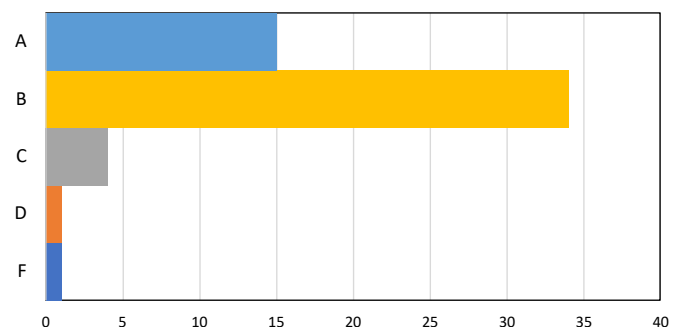

Figure 2. Post midterm exam survey results for 2018 class. (The x axis is the 'Number of Students'.)

\section{Analysis of Student Performance on Midterm Lab Exam}

In addition to the feedback from the post-midterm student survey, I (TM) was able to compare how the students performed on the different types of questions used on the case history lab midterm exam (2018 and 2019) and the traditional station lab exams (2017) (Fig. 3). I went through all the exams and determined the class percentage on each type of question. There were no significant differences between the 2018 and 2019 lab midterm exams (both case history exams; student $t$ test $p<0.05$ ) when the different question types were compared. For all question types, the case history class average was significantly higher or the same as the class average for the traditional station lab exam. In two question types (demonstrates an understanding of the lifecycle of the parasite; demonstrates knowledge on the management of the parasite) there was a significant difference between the 2017 (traditional station lab exam) and both 2018 and 2019 classes (case history lab exams), with the latter two years scoring higher. In three question types (correctly identifies the parasite; correctly identifies the location of the parasite; and demonstrates knowledge of the anatomy of the parasite) the 2019 class (case history) was significantly higher than the 2017 class (traditional). The 
2018 class (case history) was significantly higher than the 2017 class (traditional) for one question type (demonstrates knowledge of unique aspects of the parasite's biology).

\section{Pre-Final Lab Exam Survey}

In 2018, prior to the lab final exam a second anonymous voluntary survey was performed. The results are below.

Question 1 Now that you know how you did on the lab midterm exam would you have preferred to write a typical station lab exam instead of the exam based upon case histories. $92.7 \%$ No

Question 2 How many case histories would you prefer to be on the lab final exam? Select one.

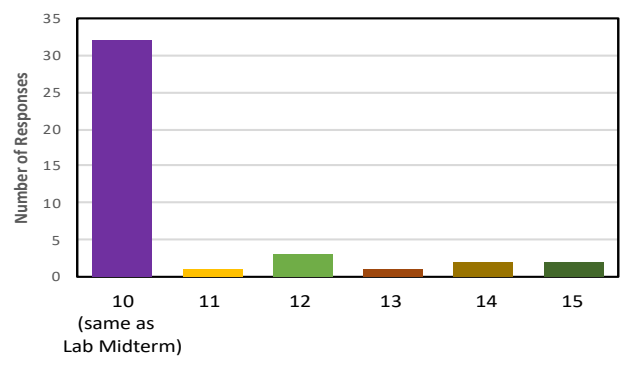

Question 3 The first lab exam was 2 hours in length. If the number of case histories was the same would you prefer (Circle one): another 15 minutes; another 30 minutes; Same amount of time.

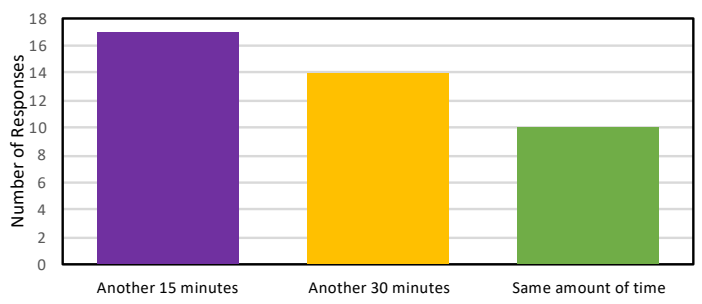

Question 4 If you could change one thing about the format of the lab final exam what would it be?

- Nothing -8 students

- Better/More photographs or diagrams -8 students

- No questions on the name of the disease caused by the parasite -5 students

- $\quad$ More time - 4 students

- Shorter exam - 1 student

- More space to write answers- 1 student

Based upon the student feedback from the pre-final exam survey, the number of case histories on the final lab exam remained the same as the midterm exam and the students were given an additional 15 minutes to complete the final lab exam in 2018, but not in 2019. In response to the request for better photographs/diagrams on the final lab exam, two copies of the exam were printed on photographic quality paper and these were available to the students throughout the exam. In 2018, the students were not asked to name the disease associated with the parasite on the lab final exam. The 2019 class did have some questions which asked them to name the disease associated with the parasite and had exams written on photographic quality paper for reference.

\section{Analysis of Student Performance on Final Lab Exam}

As with the midterm lab exam, the final lab exam student performance was compared for the traditional station exam (2017) and the case history exams (2018/2019). As with the lab midterm, when the class performance on each question type was compared and there were no significant differences between the 2018 and 2019 lab final exams (both case history exams; student test $\mathrm{p}<0.05$ ) (Fig. 4). One question type (demonstrates knowledge of the anatomy of the parasite) had a significant difference between the 2017 (traditional station lab exam) and both case history exams (2018 and 2019). In three question types (correctly identifies the disease associated with parasite (only asked in 2019); demonstrates knowledge of unique aspects of parasite's biology; demonstrates knowledge on the management of the parasite) only one of the case history classes was significantly different from the station lab exam class (Fig. 4). On closer examination of the two question types which had all three classes represented, the 2017 class was significantly higher than one of the case history classes, but not the other. But when the two case history classes were combined (Fig. 5), the traditional exam class was not significantly different from the case history classes for these two question types.

As there was no significant difference between the class percentage for the 2018 and 2019 classes, the data for these two classes was combined, as well as the midterm and final lab exams scores, in order to compare the combined case histories exams to the traditional station lab exams. Using this combined data, the case history class percentage per question type was significantly higher in three categories (correctly identifies the parasite; correctly identifies the location of the parasite; demonstrates an understanding of the lifecycle of the parasite) (student $t$ test $p<0.05$ ) or the same when compared to the traditional station lab exam class (Fig. $5)$.

The data clearly shows that the addition of the case histories to the lab improved the student performance on the lab exams. The students also preferred the case history exams to the traditional station exams. We also examined if the students had overall improved course grades. When I (TM) compared the letter grades assigned in the years that had the traditional lab exams (2014-2017) to the case history classes (2018 and 2019), it is apparent that the students' performance for the case history classes was much better for the entire course than the traditional station classes (Fig. 6). In both 2018 and 2019, the number of A's (A+, A, A-) increased compared to previous years and more importantly no one received a D or F letter grade. There was one student in 2018 and two students in 2019 which withdrew due to extenuating circumstances. 


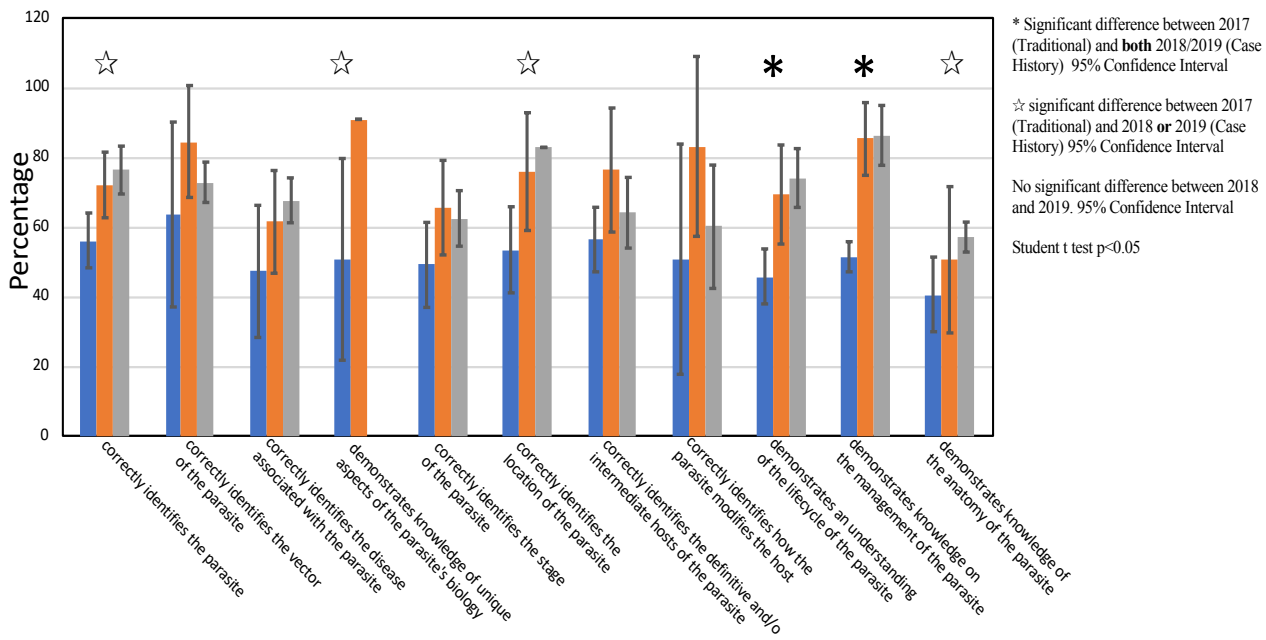

Figure 3. Comparison of the class percentage per question type on the Lab Midterm Exam for the Traditional Station Lab Exam (2017 in blue) and the Case History Lab Exams (2018 in orange and 2019 in grey). Student $t$ test $p<0.05$

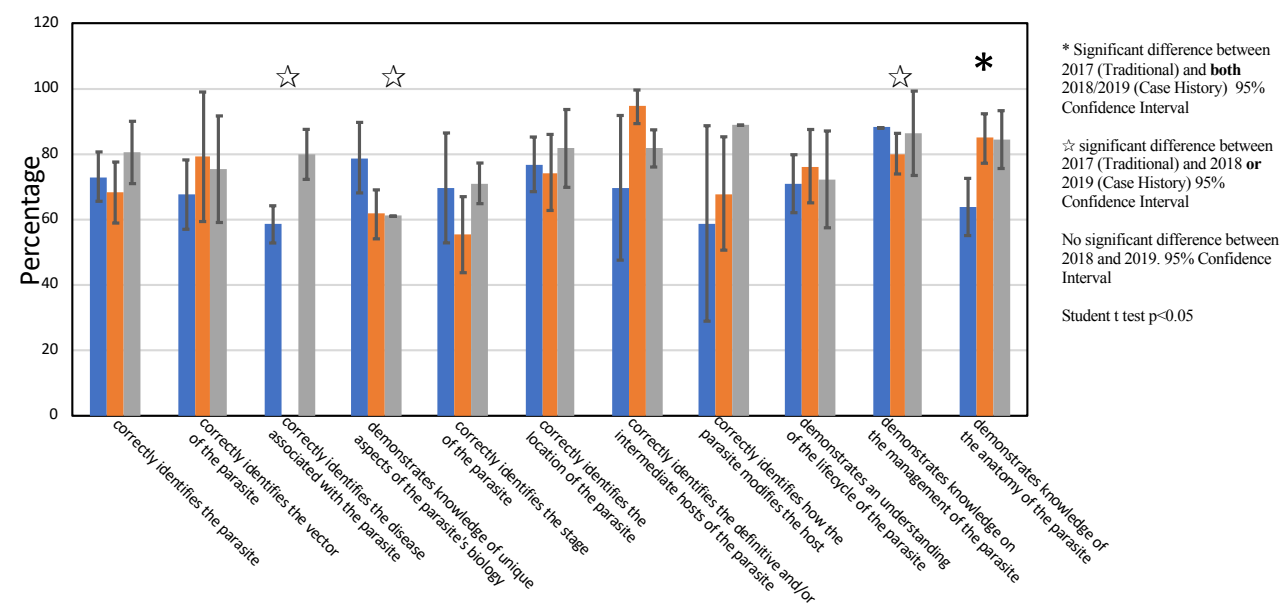

Figure 4. Comparison of the class percentage per question type on the lab final exam for the Traditional Station Lab Exam (2017 in blue) and the Case History Lab Exams (2018 in orange and 2019 in grey). Student $t$ test $<0.05$.

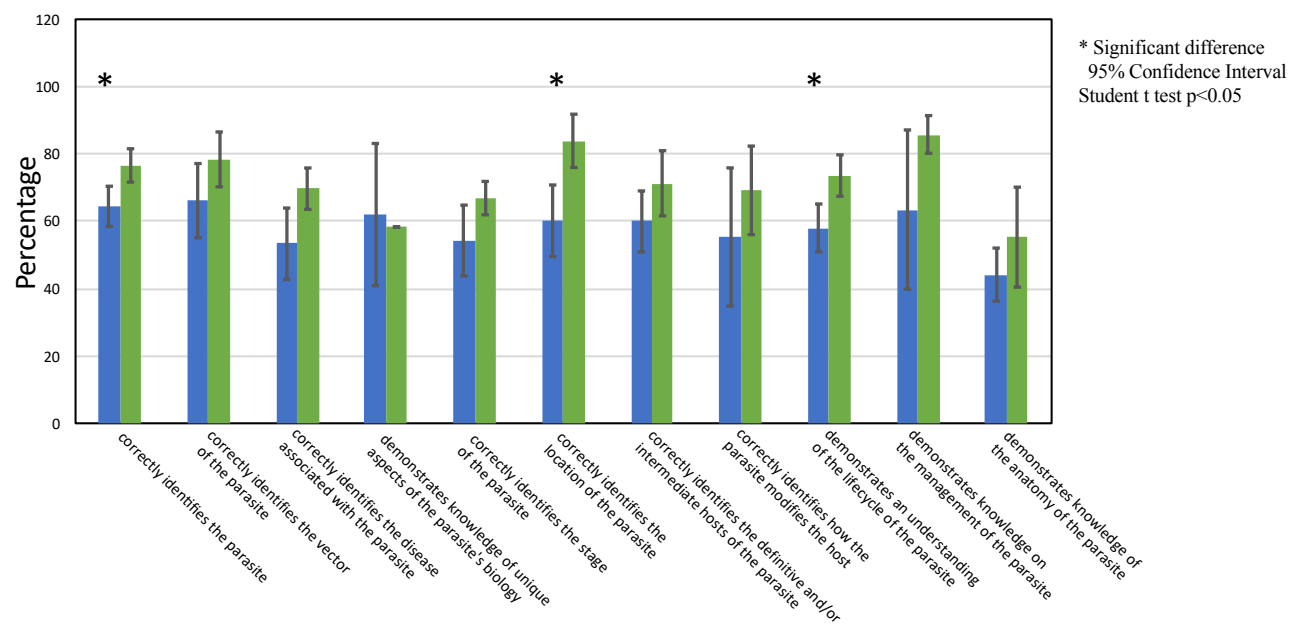

Figure 5. Comparison of the class percentage per question type for all lab exams combined (midterm and final) for the Traditional Station Lab Exam (2017 in blue) and the Case History Lab Exams (2018 and 2019 combined in green). Student $t$ test $p<0.05$. 
a) Letter Grades Distribution 2018 (Case Histories)

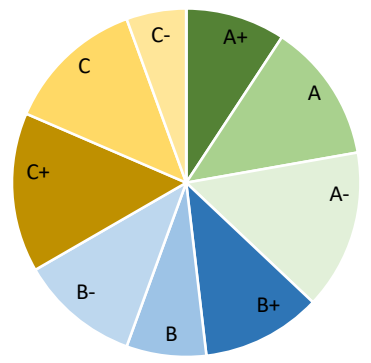

c) Letter Grade Distribution Average for 2014-2017 (Traditional Exam Classes)

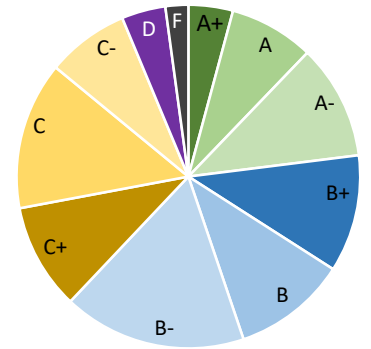

b) Letter Grade Distribution 2019 (Case Histories)

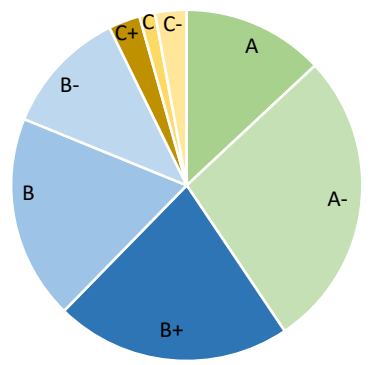

d) Letter Grade Distribution Average for $2018+2019$ (Case History Exam Classes)

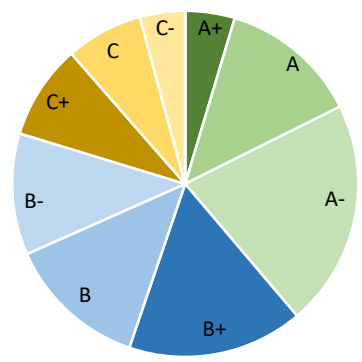

Figure 6. Course letter grade distributions. a) 2018 (Case History) b) 2019 (Case History) c) Average letter grade distribution for 2014-2017 (Traditional Lab Exams) and d) Average letter grade distribution 2018-2019 (Case History Exam Classes).

\section{Discussion}

We feel that the addition of the case histories to the lab component of the course was a great success due to the fact that the students achieved higher marks on the lab exams and appeared to enjoy working through the case histories. When we were talking to the students, we would often hear comments such as: "Now I understand why learning the life cycle of the parasite is important.", or "I can see the realworld application of the material that we are learning in this course." We believe that the case histories also helped the students remember the links between symptoms, modes of transmission and the parasite, as we would often hear "Isn't this the parasite that Bob had and it was ....". During lab review sessions in 2018 and 2019, students were able to recall much more information about the parasites then in classes with the traditional lab exam format. Anecdotally, it appeared that the case histories helped highlight differentiating factors .

We believe that the case histories required the students to come to lab with all the background reading (i.e. the lab handout) completed. In previous years, we were

certain that some students did not read the lab handout before they came to the lab. We did not get this impression when working with 2018 or 2019 students. The students seemed to come to the lab much better prepared for the work they had to do and did not leave the reading until they were cramming for the exams.

We enjoyed all the conversations we had with the students when we were discussing their answers to the questions that were posed in the case histories.

The case histories are available upon request. Please contact Tammy McMullan (tmcmulla@sfu.ca), who would be happy to share all of them.

\section{Notes for the Instructor}

Changing the format of the lab exams definitely made the exam weeks easier for the instructors. Moving away from station lab exams meant that the case history exam set up was simplified as there was little to set-up besides the desk space ( no oil immersion to clean up, and no constantly checking the microscopes during the exam to ensure the parasite was still in view). The classroom was calmer because the students did not have to move every three minutes.

We supplied the students with a world map during weekly lab sessions and on the exams, as we discovered that this was helpful for location identification for some of the case histories.

\section{Cited References}

Acholonu AWD. 2003. Trends in teaching parasitology: the American situation. Trends in Parasitology 19(1):6-9.

Dural AC, Celik MF, Temizgonul B, Unsal MG, Akarsu C, Gonenc M, Kalayci MU and Alis H. 2015. Unusual clinical case: extraluminal manifestation of a tapeworm from the eviscerated midline incision in a post-surgery patient. J. of Infection in Developing Countries 9(4):428-430.

Freemann S, Eddy SL, MacDonough M, Smith MK, Okoroafor N, Jordt H, and Wenderoth MP. 2014. Active learning increases student performance in science, engineering, and mathematics. PNAS. 111(23): 8410-8415.

Jabbar A, Gasser RB and Lodge J. 2016. Can new digital technologies support parasitology teaching and learning? Trends in Parasitology 32(7):522-530.

Zibaei M, Firoozeh F, and Azargoon A. 2012. Infantile Amoebiasis: A Case Report. Case Reports in Infectious Diseases. Article ID 614398, 3 pages. doi:10.1155/2012/614398. 


\section{Acknowledgments}

We would like to thank the BISC318 students for embracing the changes to the lab, Nicolas Salcedo for 2019 course teaching assistance, Tiia Haapalainen for ensuring that we had all the specimens we needed for the lab sessions and Dr. Carl Lowenberger for starting the conversation of changing the format of the lab component of the course.

\section{About the Authors}

Tamila (Tammy) McMullan has been a Teaching Faculty member at the Simon Fraser University since 1990, where she teaches first year courses, third year natural history courses and the field courses for the Masters of Pest Management Program.

Heather Coatsworth recently obtained her $\mathrm{PhD}$ from Simon Fraser University under the supervision of Dr. Carl Lowenberger. She is now a post-doctoral fellow at the University of Florida (Dinglasan Lab, FL, USA) where she continues to research host-pathogen interactions, as well as guest lectures in Human Parasitology courses. 


\section{Mission, Review Process \& Disclaimer}

The Association for Biology Laboratory Education (ABLE) was founded in 1979 to promote information exchange among university and college educators actively concerned with teaching biology in a laboratory setting. The focus of ABLE is to improve the undergraduate biology laboratory experience by promoting the development and dissemination of interesting, innovative, and reliable laboratory exercises. For more information about ABLE, please visit http://www.ableweb.org/。

Advances in Biology Laboratory Education is the peer-reviewed publication of the conference of the Association for Biology Laboratory Education. Published articles and extended abstracts are evaluated and selected by a committee prior to presentation at the conference, peer-reviewed by participants at the conference, and edited by members of the ABLE Editorial Board. Published abstracts are evaluated and selected by a committee prior to presentation at the conference.

\section{Citing This Article}

McMullan TL, Coatsworth H. 2020. Using case histories to teach parasitology labs. Article 74 In: McMahon K, editor. Advances in biology laboratory education. Volume 41. Publication of the 41st Conference of the Association for Biology Laboratory Education (ABLE). https://doi.org/10.37590/able.v41.art74

Compilation (C) 2020 by the Association for Biology Laboratory Education, ISBN 1-890444-17-0. All rights reserved. No part of this publication may be reproduced, stored in a retrieval system, or transmitted, in any form or by any means, electronic, mechanical, photocopying, recording, or otherwise, without the prior written permission of the copyright owner.

ABLE strongly encourages individuals to use the exercises in this volume in their teaching program. If this exercise is used solely at one's own institution with no intent for profit, it is excluded from the preceding copyright restriction, unless otherwise noted on the copyright notice of the individual chapter in this volume. Proper credit to this publication must be included in your laboratory outline for each use; a sample citation is given above. 